\title{
块状和少层黑磷的合成
}

徐林

南京师范大学化学与材料科学学院, 南京 210023

\section{Synthesis of Bulk and Thin-Layer Black Phosphorus}

\section{Lin Xu}

School of Chemistry and Materials Science, Nanjing Normal University, Nanjing 210023, P. R. China.

Email: xulin001@njnu.edu.cn.

Published online: December 26, 2019.

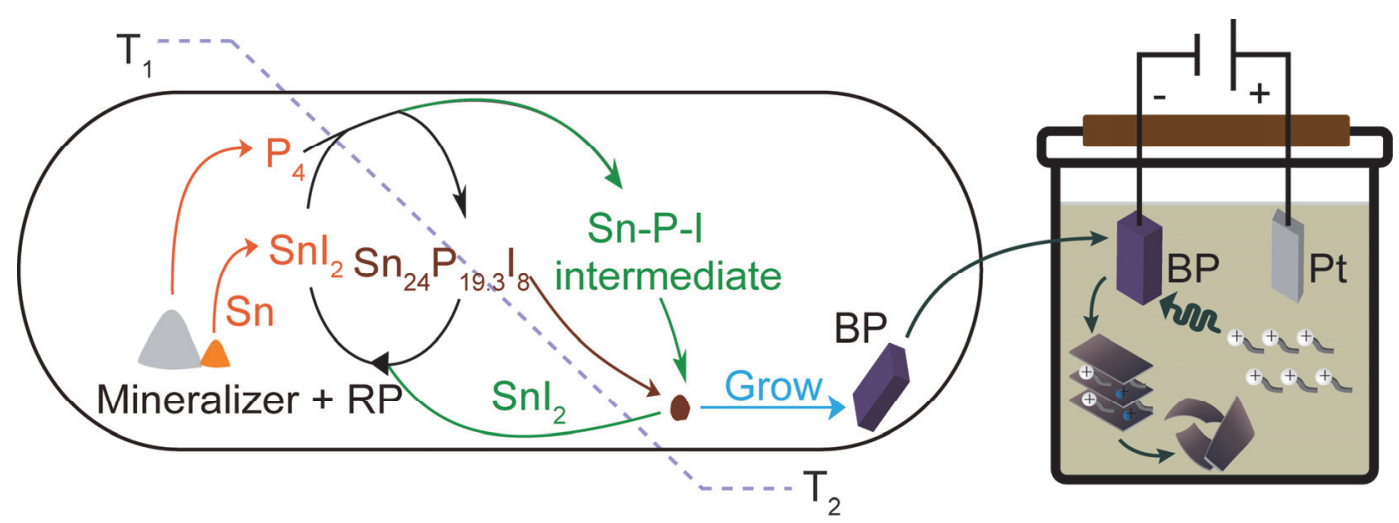

块状黑磷合成及电化学剥离制备少层黑磷示意图 ${ }^{3,4}$ 。

黑磷(Black Phosphorus, BP)具有层状结构, 而 少层黑磷作为一种二维材料, 则具有各向异性和 随层数可调的性质。与石墨烯相比, 黑磷具有可调 的带隙; 而与过渡金属二硫化物相比, 黑磷具有较 高的载流子迁移率, 因此黑磷在半导体领域崭露 头角。黑磷亦具有光热特性和优异的生物相容性, 在生物领域如肿瘤治疗等方面应用前景广阔。此 外, 黑磷的电学和层状性质也促进了其在能源领 域的应用。然而, 目前黑磷的可控合成仍然颇具挑 战, 限制了其进一步发展。

最初, 黑磷由红磷(Red Phosphorus, RP)或白 磷在高温高压条件下合成, 直至2007年, 化学气相 传输法(Chemical Vapor Transport, CVT)首次被应 用于块状黑磷的合成。与高温高压法相比, 该方法 较温和, 且获得的黑磷品质较高, 因此长期被用于 块状黑磷合成 ${ }^{1}$ 然而, 黑磷在应用于各领域时, 多 为少层黑磷, 因此少层黑磷的制备更为关键 ${ }^{2}$ 。
近期, 南京工业大学谢小吉教授课题组对块 状和少层黑磷的可控制备做了一系列探索。他们 用电化学法自上而下地对块状黑磷进行剥离, 剥 离过程在水相体系中进行, 阳离子表面活性剂十 六烷基三甲基氯化铵作为电解质, 块状黑磷作为 阴极, 铂网作为阳极, 施加 $30 \mathrm{~V}$ 电压后, 块状黑磷 立刻被剥离, 体系迅速变浑浊。通过产物表征他们 发现, 十六烷基三甲基铵阳离子在电场作用下插 层进入块状黑磷并分解产生气体, 从而克服黑磷 层间的范德华作用力, 形成少层黑磷(层数 $\approx 10)^{3}$ 。 特别地, 十六烷基三甲基铵阳离子吸附在少层黑 磷表面, 对其结构形成保护, 使其能在水溶液中稳 定存在1-2周。而洗去阳离子后, 少层黑磷可以直 接被应用, 延长了其保存和使用周期。

通过自上而下途径剥离块状黑磷获得的少层 黑磷尺寸一般在微米级以下, 而在实际应用中, 大 面积的少层黑磷薄膜则更具优势。自下而上途径, 
如化学气相沉积法 (Chemical Vapor Deposition, CVD), 常被用来制备二维材料薄膜, 然而大面积少层黑磷薄膜的合成尚未实现。这是 因为不同于石墨烯和过渡金属二硫化物，黑磷的 生长需要活性位点, 且其生长机理尚不明确。谢小 吉教授课题组通过调控化学气相传输法中使用的 矿化剂, 对黑磷生长过程、产物上的生长活性位点 进行表征, 提出反应过程中, 矿化剂先形成少量 $\mathrm{Sn}_{24} \mathrm{P}_{19.3} \mathrm{I}_{8}$, 在这个活性位点上, 气态 $\mathrm{P}_{4}$ 分子以类似 聚合的方式外延生长, 形成块状黑磷 ${ }^{4}$ 。这一研究 明确了黑磷生长的活性位点, 对少层黑磷的自下 而上生长具有指导意义。

基于对本领域的探索和理解, 谢小吉课题组 以黑磷和过渡金属二硫化合物为例, 对化学气相 传输法用于二维材料的合成进行了总结。未来, 希 望利用成熟但并不热门的化学气相传输法, 通过 调控反应温度, 控制传输速率, 引入活性位点和高 取向性的基板材料等措施调控黑磷的生长，以期实 现大面积少层黑磷的可控合成，促进其广泛应用。

此外该课题组还与南京工业大学董晓臣教授 课题组合作探索了黑磷在光热/光动力协同肿瘤治 疗方面的应用 ${ }^{5}$; 与南京工业大学朱纪欣教授课题 组合作研究了黑磷在锂离子电池方面的应用 6 。上
述相关研究成果发表在Small, ACS Applied Nano Materials, Frontiers in Chemistry, Chemical Science, Journal of Power Sources 等期刊上 ${ }^{2-6}$ 。这 一系列工作将加深人们对于黑磷合成的理解与认 知，促进大面积少层黑磷薄膜的可控合成。

\section{References}

(1) Lange, S.; Schmidt, P.; Nilges, T. Inorg. Chem. 2007, 46, 4028 doi: $10.1021 /$ ic $062192 q$

(2) Wang, D.; Luo, F.; Lu, M.; Xie, X.; Huang, L.; Huang, W. Small 2019, 15, 1804404. doi: 10.1002/smll.201804404

(3) Luo, F.; Wang, D.; Zhang, J.; Li, X.; Liu, D.; Li, H.; Lu, M.; Xie, X.; Huang, L.; Huang, W. ACS Appl. Nano Mater. 2019, 2, 3793. doi: 10.1021/acsanm.9b00667

(4) Wang, D.; Yi, P.; Wang, L.; Zhang, L.; Li, H.; Lu, M.; Xie, X.; Huang, L.; Huang, W. Front. Chem. 2019, 7, 21. doi: $10.3389 /$ fchem. 2019.00021

(5) Yang, X.; Wang, D.; Zhu, J.; Xue, L.; Ou, C.; Wang, W.; Lu, M.; Song, X.; Dong, X. Chem. Sci. 2019, 10, 3779. doi: 10.1039/c8sc04844d

(6) Li, D.; Wang, D.; Rui, K.; Ma, Z.; Xie, L.; Liu, J.; Zhang, Y.; Chen, R.; Yan, Y.; Lin, H.; et al. J. Power Sources 2018, 384, 27. doi: 10.1016/j.jpowsour.2018.02.069 